\title{
A Discourse Analysis Method at The Service of the Peer Teaching Observation: The Development of a Tool to Optimize Teaching Practices
}

\author{
Luigina Mortari ${ }^{1}$, Roberta Silva ${ }^{2}$, Alessia Bevilacqua ${ }^{3}$, Fedra Alessandra Pizzato $^{4}$ \\ University of Verona (Italy)
}

\begin{abstract}
:
Peer teaching observation (PTO) is a developmental evaluation method that, stimulating critical reflection on teaching practice, can offer feedbacks aimed at promoting their improvement. An increasing number of Higher Education institutions have adopted this method because of its transformative potential but, despite that, PTO is far from being a standard. From the still ongoing debate about the tools that could be used to conduct these analyses, emerges the need to choose a tool able to a) be flexible enough to adapt itself to different teaching practices effectively; b) return to the observed teacher feedback capable of increasing his/her awareness about the teaching practices he/she implements.

The tool that the Teaching and Learning Center of the University of Verona developed and tested to respond to these needs effectively places the principles of the discourse analysis method at the service of peer teaching observation. We, therefore, work within a framework oriented towards developmental evaluation.

This paper presents how this tool can be used to capture discursive actions within the teaching practice, to give the observed teacher a clear image of his/her teaching style, and what is its effect on the teacher-student interaction. Moreover, we show how the results of this analysis can be used, by the observed and the observing teacher, to design a program of intervention aimed at optimizing the teaching process, according to a developmental framework.
\end{abstract}

Keywords: Higher Education; Developmental Evaluation; Discursive practices; Teaching and Learning Center; Teaching Development. 